\title{
SISTEM KEAMANAN BAGI KENDARAAN DENGAN RFID BERBASIS ARDUINO UNO
}

\author{
Ibrahim ${ }^{1)}$, Arafat ${ }^{2)}$ \\ ${ }^{1}$ Fakultas Teknologi Informasi, Universitas Islam Kalimantan Muhammad Arsyad Al Banjari Banjarmasin \\ Email : Terrasin06@gmail.com \\ ${ }^{2}$ Fakultas Teknologi Informasi, Universitas Islam Kalimantan Muhammad Arsyad Al Banjari Banjarmasin \\ Email : aaruniska@gmail.com
}

\begin{abstract}
Abstrack
Kendaraan bermotor merupakan transportasi yang sangat umum digunakan di Indonesia. Namun kendaraan bermotor bukanlah barang yang tergolong murah. Banyak kasus pencurian kendaran bermotor terjadi di Indonesia. Meskipun telah dilengkapi dengan keamanan kunci, dan penutup lubang kunci pada sepeda motor, kasus pencurian masih marak terjadi. Maka dari itu, dibutuhkan sistem keamanan yang lebih canggih.Sistem pengaman kendaraan bermotor menggunakan RFID dapat menjadi solusi. Sistem ini memakai RFID sebagai keamanan tambahan dan mampu memgirimkan pemberitahuan berupa bunyi alarm apabila kendaraan digunakan tanpa sepengetahuan dari pemilik. Untuk mengurangi terjadinya pencurian sepeda motor, dengan alat sistem keamanan ini akan di letakan di bagian kendaraan bermotor yang akan di tambahakan alat, dengan cara menggunakan Keychain, yang menggunakan prangkat arduino. Dengan sistem ini diharapkan bisa mengurangi terjadinya pencurian sepeda motor yang marak terjadi di masa kini, Dengan perancangan sistem pada alat tersebut akan tercipta sebuah alat yang dapat mengurangi terjadinya pencurian sepeda motor dan mengurangi kerugian materi pada pengguna kendaraan bermotor, dan keamanan lebih terjamin dengan angka keamanan mencapai $85 \%$.
\end{abstract}

Kata Kunci: RFID, Arduino, Keychain, Sistem Keamanan

\section{PENDAHULUAN}

Kebutuhan masyarakat kita terhadap keamanan kendaraan terutama kendaraan sepeda motor cukup besar. Hal ini dikarenakan keamanan pada kendaraan sepeda motor merupakan salah satu komponen utama yang sangat dibutuhkan, sebab supaya tidak terjadinya curian motor yang terjadi saat ini. sehingga sangat penting untuk kita agar tidak terjadi pencurian motor yang terjadi saat ini. Saat ini kebutuhan konsumen terhadap kendaraan, terutama sepeda motor sangat dibutuhkan, untuk kebutuhan dan kegiatan sehari-hari, yang tidak memerlukan begitu banyak waktu untuk kesuatu tujuan yang kita tuju. Produsen otomotif terutama kendaraan sepeda motor setiap tahunya memproduksi kendaraan sepeda motor dengan berbagai macam produk. Produsen biasanya menggunakan kunci ganda motor yang mengunakan sistem mekanika yang menggunakan kunci pada umumnya. jenis inilah yang dihitung sangat kurang keamanannya dan sangat kurang efektif untuk kendaraan sepeda motor, itu bisa dibuktikan dengan adanya laporan pencurian motor yang setiap tahunnya meningkat.

Di lingkungan kita prilaku produsen terhadap produk ini bisa digolongkan sebagai prilaku yang kurang efektif terhadap pada keamanan kendaraan sepeda motor. Hal ini dikarenakan masyarakat atau konsumen kita banyak mengalami pencurian motor, terutama kendaraan sepeda motor. Produsen otomotif kebanyakan menganggap sistem keamanan di setiap kendaraan sepeda motor, tidak terlalu dipermasahlahkan. Padahal sebenarnya pihak konsumen atau masyarakat membutuhkan sistem keamanaan yang canggih. Dengan adanya teknologi yang semakin berkembang setiap tahunnya maka sistem keamanan di kendaraan sepeda motor bisa di realisasikan dan menjadi kenyataan..

Atas dasar latar belakang tersebut maka akan dirancang dan direalisasikan sebuah alat yang diharapkan mampu menangani atau mengurangi pencurian motor yang kerap terjadi dilingkungan ini. Alat ini dirancang untuk sistem 
keamanan pada kendaraan sepeda motor dengan keamanan berbasis RFID yang dihubungkan pada motor dan peringatan melalui bunyi alarm, dengan menggunakan Keychain, Alat ini dirancang untuk menerapkan konsep microcontroller. Metode ini dipilih karena teknologi ini merupakan teknologi yang bisa mengurangi pencurian kendaraan sepeda motor yang nantinya bisa mengurangi terjadinya pencurian kendaraan sepeda motor. Selain itu teknologi ini juga lebih mudah dan diaplikasikan dibandingkan dengan teknologi yang ada saat ini yang di pake kendaraan sepeda motor dengan menggunakan kunci pada umumnya.

\section{METODE PENELITIAN}

\section{Tahapan Penelitian}

Penelitian ini dilakukan berdasarkan tahapantahapan penting yang dikerjakan dengan berorientasikan kepada indikator keberhasilan dalam menghubungkan RFID dengan wiring kendaraan sehingga dapat digunakan untuk menyelesaikan permasalahan multi objektif. Untuk dapat mencapai, indikator tersebut, maka tahapan-tahapan penelitian ini adalah sebagai berikut :

1. Analisa masalah, dalam hal ini kebutuhan menganalisa permasalahan yang akan diteliti mengenai penggabungan RFID dengan wiring kendaraan.

2. Analisa kebutuhan, dalam hal ini segala kebutuhan dalam meneliti baik dari jurnal, buku, literatur-literatur, alat dan bahan.

3. Mendesain alat yang akan dibangun dengan menggunakan RFID dengan wiring kendaraan.

4. Membuat program dengan menggunakan arduino IDE

5. Menguji alat dengan kode program yang dibuat.

6. Menguji alat yang dibuat dengan starter kendaraan.

7. Membuat laporan dan menyimpulkan hasil penelitian

\section{Alat dan Bahan}

Adapun Alat dan bahan yang di gunakan dalam proses pembuatan rangkaian pengkat ini adalah:

1. RFID Tag (Keychain atau Card) dan

RFID reader menggunakan MC522.

RFID atau Radio Frequency Identification adalah teknologi yang menggunakan gelombang radio untuk mengidentifikasi manusia atau objek secara otomatis. Metode yang paling sering digunakan adalah untuk menyimpan serial number yang menunjukkan identitas seseorang atau benda, pada sebuah microchip yang disertakan pada antena (chip dan antena adalah RFID trans ponder atau sebuah tag RFID). Melalui antena, chip mentransmisikan informasi identifikasi kepada reader . Kemudian reader mengubah pantulan gelombang radio dari tag RFID kedalam informasi digital yang dapat dilewati pada komputer yang akan menggunakannya.

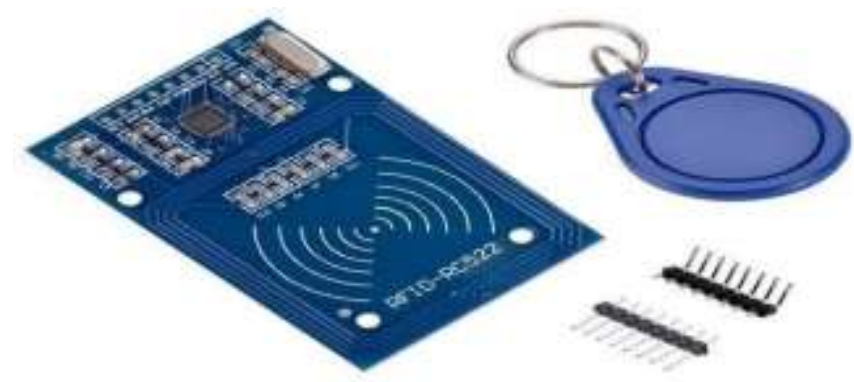

2. Modul Relay 1 channel 5v.

Relay adalah Saklar (Switch) yang dioperasikan secara listrik dan merupakan komponen Electromechanical (Elektromekanikal) yang terdiri dari 2 bagian utama yakni Elektromagnet (Coil) dan Mekanikal (seperangkat Kontak Saklar/Switch). Relay menggunakan Prinsip Elektromagnetik untuk menggerakkan Kontak Saklar sehingga dengan arus listrik yang kecil (low power) dapat menghantarkan listrik yang bertegangan lebih tinggi. Sebagai contoh, dengan Relay yang menggunakan Elektromagnet $5 \mathrm{~V}$ dan $50 \mathrm{~mA}$ mampu menggerakan Armature Relay (yang berfungsi sebagai saklarnya) untuk menghantarkan listrik 220V 2A.

Modul relay ini dapat digunakan sebagai switch untuk menjalankan berbagai peralatan elektronik. Misalnya Lampu listrik, Motor listrik, dan berbagai peralatan elektronik lainnya Kendali ON / OFF switch (relay), sepenuhnya ditentukan oleh nilai output sensor, yang setelah diproses Mikrokontroler akan menghasilkan perintah 
kepada relay untuk melakukan fungsi ON / OFF.

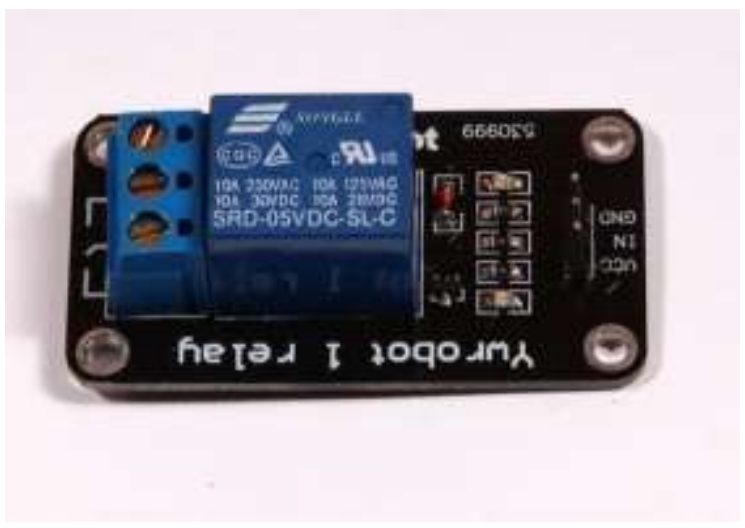

3. Modul buzzer passive

Buzzer adalah sebuah komponen elektronika yang berfungsi untuk mengubah getaran listrik menjadi getaran suara. Pada dasarnya prinsip kerja buzzer hampir sama dengan loud speaker, jadi buzzer juga terdiri dari kumparan yang terpasang pada diafragma dan kemudian kumparan tersebut dialiri arus sehingga menjadi elektromagnet, kumparan tadi akan tertarik ke dalam atau keluar, tergantung dari arah arus dan polaritas magnetnya, karena kumparan dipasang pada diafragma maka setiap gerakan kumparan akan menggerakkan diafragma secara bolakbalik sehingga membuat udara bergetar yang akan menghasilkan suara. Buzzer biasa digunakan sebagai indikator bahwa proses telah selesai atau terjadi suatu kesalahan pada sebuah alat (alarm).

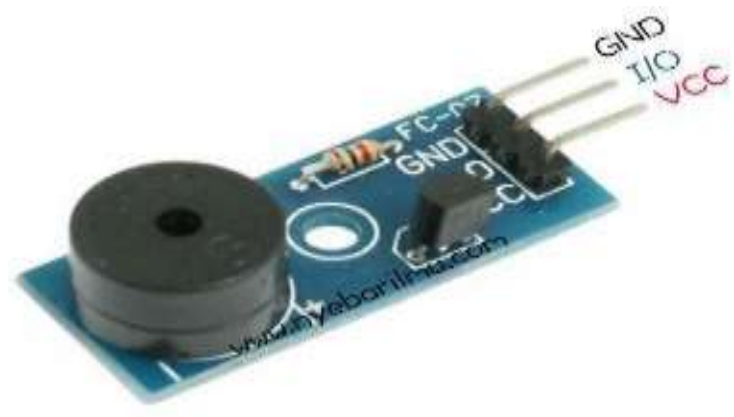

4. Breadboard

5. Arduino Uno

6. S50 Keychain

7. Kabel Jumper

8. LCD $16 \times 2$ menggunakan driver i2c lcd

9. Komputer dan Software IDE Arduino
Pada Konsep yang akan diambil yaitu ketika motor dihidupkan menggunakan kunci konvesional, kemudian motor hanya dapat distarter jika sudah TAP RFID dan aksesnya diterima atau terdaftar. Selain dapat diaplikasikan ke motor (misalnya honda, yamaha), sistem ini dapat juga diaplikasikan ke dalam mobil seperti mobil toyota, honda, mitsubishi, hyundai, dan lain-lain. Dikarenakan hanya diaplikasikan pada pemutus dan penyambung kabel untuk kendali starternya. Jika Keychain yang di TAP kan tidak sesuai selama 3 kali maka buzzer akan berbunyi, dan untuk mematikannya yaitu mematikan sistem kontak motor ke OFF saja.

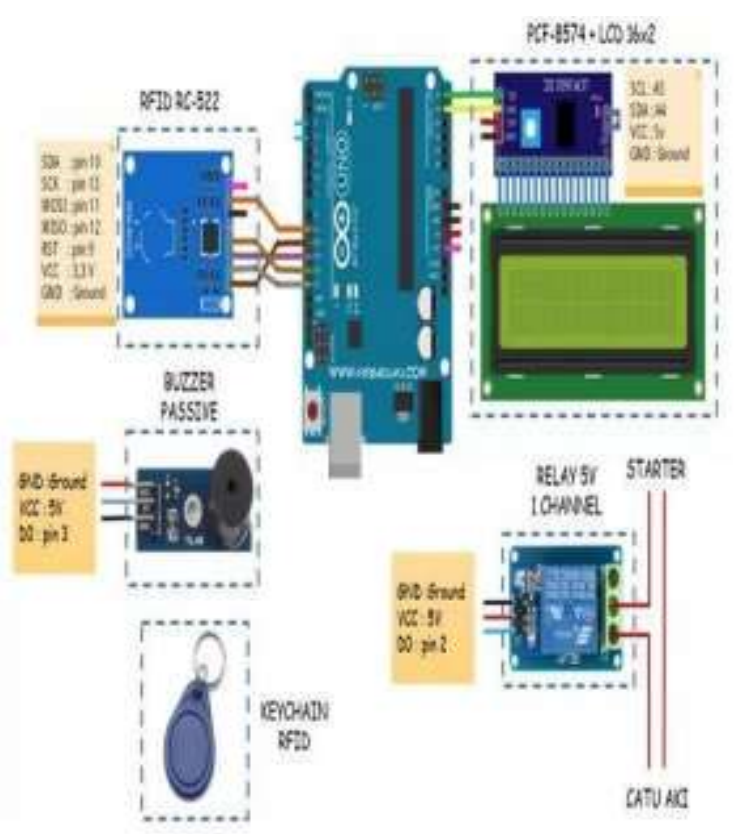

3. HASIL DAN PEMBAHASAN

\section{Simulasi}

Untuk bisa mengatur rangkaian perangkat Arduino uno maka diperlukan sebuah Software khusus bernama Software IDE Arduino yang harus di install di computer, Dengan software ini kita bisa memberikan perintah kepada rangkaian perangkat Arduino uno seperti tampilan huruf, angka, serta kalimat yang kita ingin kan supaya bisa tampil di layer LCD.

\section{Perancangan Sistem}

Jurnal Ilmiah "Technologia” 


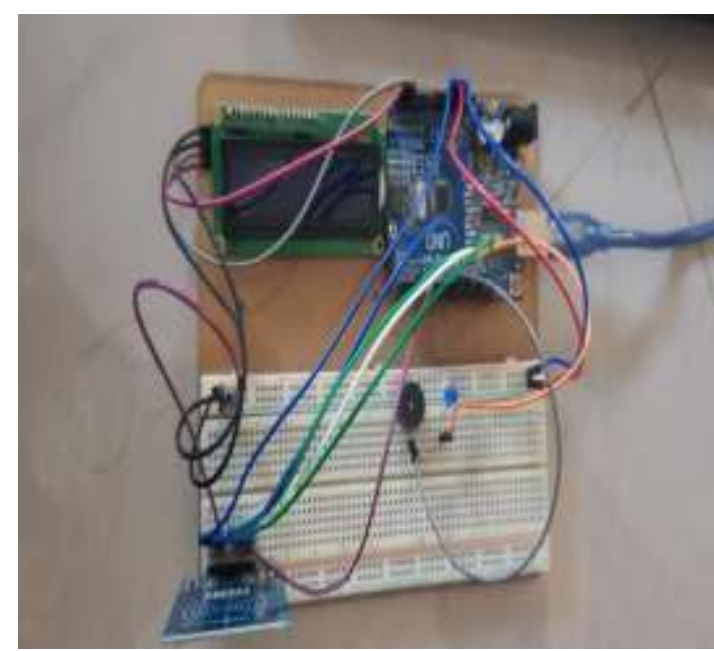

Team sudah melakukan simulasi dan uji coba sederhana pada rangkaian yang di buat serta menghubungkan rangkain dengan software IDE Arduino yang ada di computer dan hasil pengujian nya berhasil.
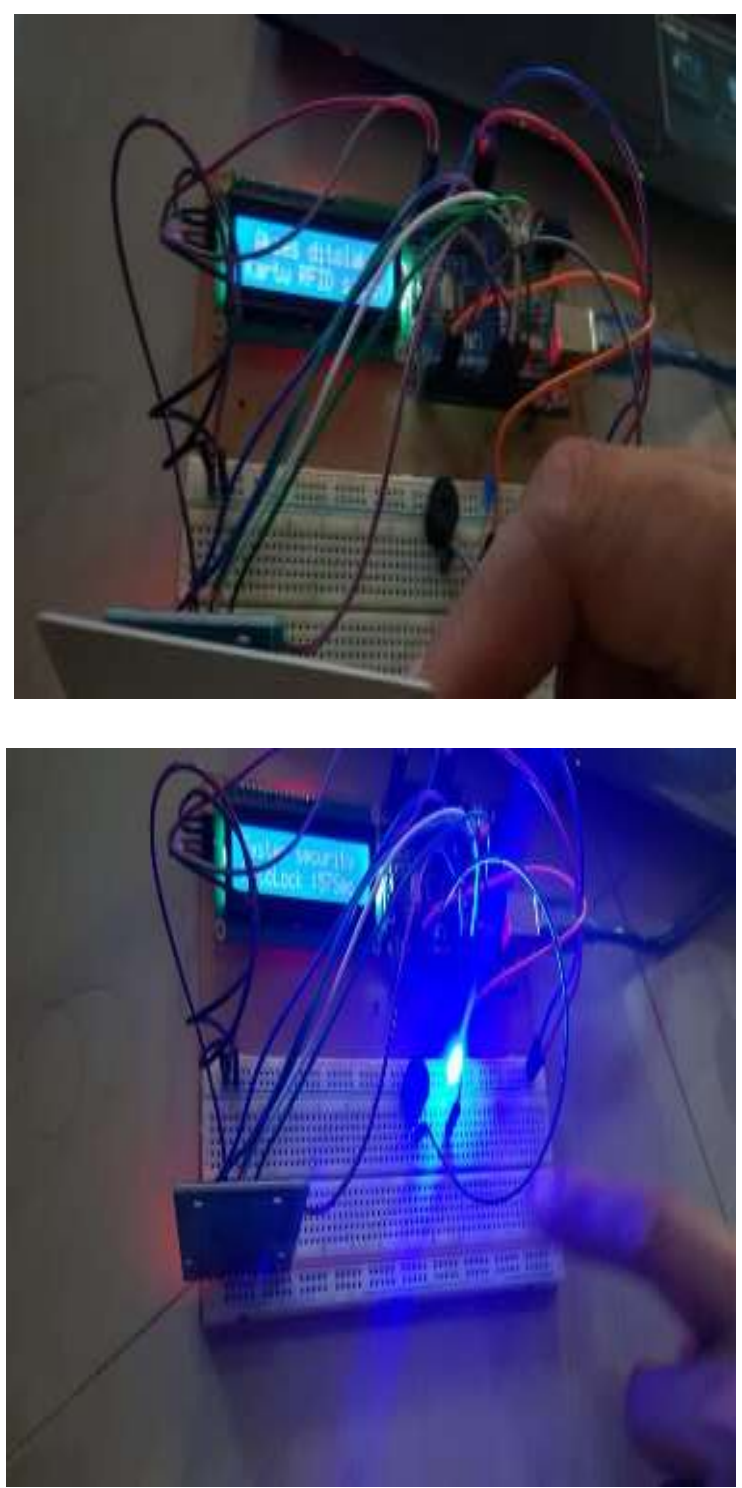

\section{Implementasi}

Pada tahap ini peneliti sudah melakukan pengujian rangkaian Arduino uno dan RFID di kendaraan matic Honda Vario dengan menghubungkan beberapa wiring kabel di aki kendaraan dan mendapatkan hasil yang memuaskan yaitu kendaraan tidak bisa dihidupkan apabila tidak memiliki akses untuk membuka kunci pengaman RFID.

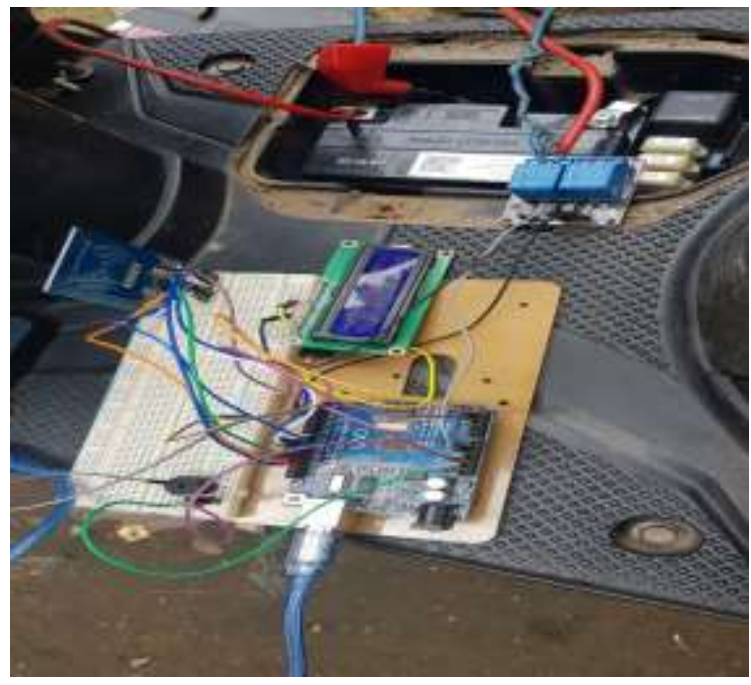

Cara kerjanya yaitu ketika motor dihidupkan menggunakan kunci konvesional, kemudian motor hanya dapat di-starter jika sudah TAP RFID dan aksesnya diterima atau terdaftar. Selain dapat diaplikasikan ke motor (misalnya honda, yamaha), sistem ini dapat juga diaplikasikan ke dalam mobil seperti mobil toyota, honda, mitsubishi, hyundai, dan lain-lain. Dikarenakan hanya diaplikasikan pada pemutus dan penyambung kabel untuk kendali starternya.

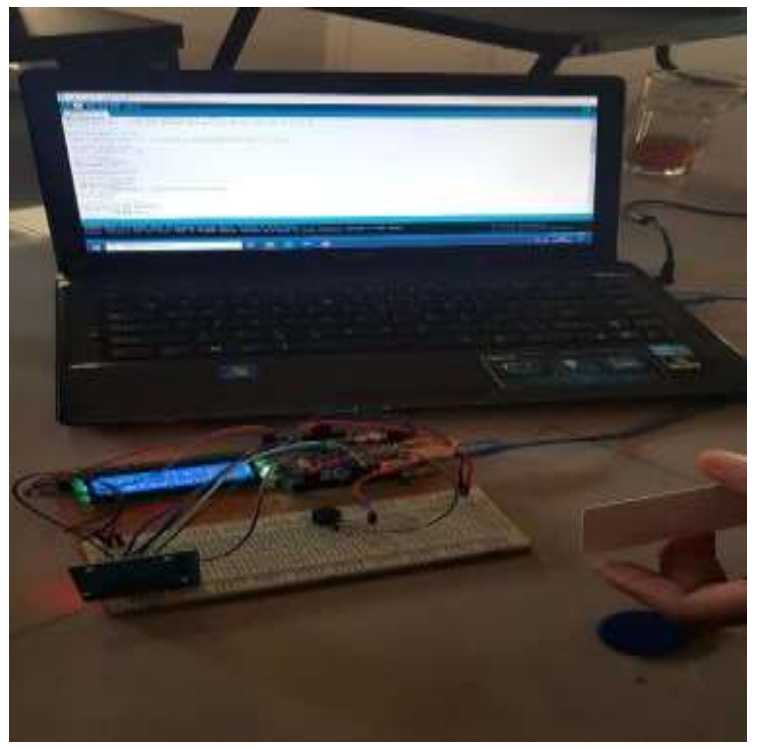


Jika Keychain yang di TAP kan tidak sesuai selama 3 kali maka buzzer akan berbunyi, dan untuk mematikannya yaitu mematikan sistem kontak motor ke OFF saja.

Namun ada beberapa catatan saat pengimplementasian yaitu kabel untuk menghubungkan rangkaian dengan catuan AKI harus pakai kabel yang besar sehingga bisa menggangkat daya saat kendaraan dihidupkan, serta perlu penelitian lanjutan untuk bisa mengakali letak posisi rangkaian arduino agar bisa aman dalam body kendaraan.

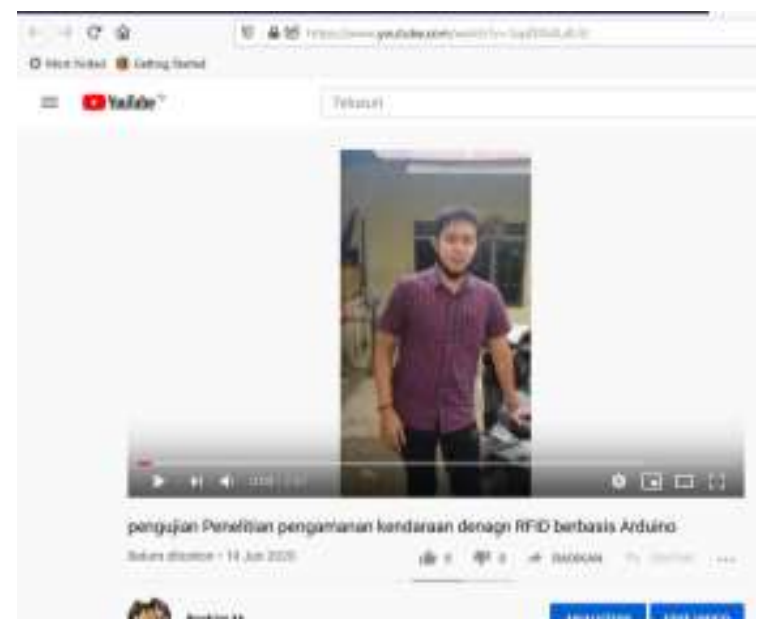

Berikut saya sertakan proses pengujian kedalam vidio yang di ungah di youtube akun saya denganhttps://www.youtube.com/watch? $\mathrm{v}=3 \mathrm{xp}$ DIG4LdUU.

\section{KESIMPULAN}

Kendaraan bermotor merupakan barang yang tergolong mahal. Banyak kasus pencurian kendaraan bermotor terjadi di Indonesia. Meskipun telah dilengkapi dengan keamanan kunci, dan penutup lubang kunci pada sepeda motor, kasus pencurian masih marak terjadi. Maka dari itu, dibutuhkan sistem keamanan yang lebih canggih.Sistem pengaman kendaraan bermotor menggunakan RFID dapat menjadi solusi. Sistem ini memakai RFID sebagai keamanan tambahan dan mampu memgirimkan pemberitahuan berupa bunyi alarm apabila kendaraan digunakan tanpa sepengetahuan dari pemilik

Untuk mengurangi terjadinya pencurian sepeda motor, dengan alat sistem keamanan ini akan di letakan di bagian kendaraan bermotor yang akan di tambahkan alat, dengan cara menggunakan Keychain, yang menggunakan prangkat arduino. Dengan sistem ini diharapkan bisa mengurangi terjadinya pencurian sepeda motor yang marak terjadi di masa kini, Dengan perancangan sistem pada alat tersebut akan tercipta sebuah alat yang dapat mengurangi terjadinya pencurian sepeda motor dan mengurangi kerugian materi pada pengguna kendaraan bermotor, dan keamanan lebih terjamin dengan angka keamanan mencapai $85 \%$ Namun ada beberapa catatan saat pengimplementasian yaitu kabel untuk menghubungkan rangkaian dengan catuan AKI harus pakai kabel yang besar sehingga bisa menggangkat daya saat kendaraan dihidupkan.

\section{REFERENSI}

[1] S Budiharjo, S Milah. (2013). Akademi Telkom Sandhy Putra Jakarta.

[2] W Bagye, $T$ Azizah. (2008). Jurnal Informatika e-journal.stmiklombok.ac.id.

[3] P. Tirumala Rao, S. Koteswarao Rao , G. Manikanta and S. Ravi Kumar . Distinguishing Normal and Abnormal ECG Signal .Indian Journal of sience and Technology, Vol 9(10), DOI: 10.17485/ijst/2016/v9i10/85449, March 2016 ..

[4] https://www.nyebarilmu.com/how-to-makesystem-security-on-motorcycle- using-rfidarduino/.

[5]http://nandasyaputra77.blogspot.com/2017/0 4/modul-relay.html

Jurnal Ilmiah "Technologia” 